\title{
An Empirical Test on Linkage Between Foreign Exchange Market and Stock Market: Evidence from Hungary, Czech Republic, Poland and Romania
}

\author{
Ngo Thai Hung, (PhD student) \\ Corvinus University of Budapest, Hungary
}

Doi: 10.19044/esj.2017.v13n31p25 URL:http://dx.doi.org/10.19044/esj.2017.v13n31p25

\begin{abstract}
The paper aims to examine the causal relationship between the stock prices and exchange rates in Hungary, Czech Republic, Poland and Romania. The investigation employs Granger's Causality test and Vector Auto Regression technique on monthly stock return and the foreign exchange rate for the period October 31, 2008 to September 18, 2017. The major findings of the study that there is no Granger's causality between the exchange rate return and stock return in these countries. The study also uses Vector Auto Regression modeling to confirm that though stock return and exchange rate are related to each other but any consistent relationship does not exist between them. Our results have provided beneficial information for investors, government policies and researchers.
\end{abstract}

Keywords: Exchange Rate, Stock Price, Granger's Causality, Vector Auto Regression

\section{Introduction}

Causal relationship between stock prices and exchange rates has received a considerable attention of researchers and policymakers starting in the early 1990s. The literature approaches on this issue have been documented in various results and explanation about the link between the two variables. Based on previous survey scholars came to agree that there is the existence of relationship between stock prices and exchange rates. According to (Granger et al., 2000), there are two kinds of theoretical approaches to the issue of the direction of the linkage between stock prices and exchange rates: stock oriented models and flow oriented models.

Before finding out the relationship between these two variables in Hungary, Czech Republic, Poland and Romania, the requirement of the relevant institutional context is supposed to be understood. All these countries were socialist economies for several decades of the $20^{\text {th }}$ century 
and formed the so-called Eastern bloc, then they have a common characteristic. Therefore, it is meaningful to investigate whether the link between stock markets and foreign exchange rates or not.

The objective of this paper is to examine the causal relations between stock prices and exchange rates for financial market in Eastern European Countries. After the introduction section, the empirical illustration will demonstrate how the Granger's Causality and Vector Auto Regression technique approach reveals, and how the issues of the link between stock return and exchange rate return have been organized. The rest of the paper proceeds as follows: the literature review, methodology, and empirical results. Finally, we conclude with the implications for policy makers.

\section{Literature Review}

During the past decades, existing literature already proposed an alternate outlook on relationship between stock prices and exchange rates. The first study made by (Franck and Young, 1972) showed that there was no significant interaction between the variables. (Aggarwal, 1981) noted a positive correlation between exchange rates of US dollar and changes in the indices of US stock prices when he studied the relationship of these variables. (Solnik, 1987) concluded a negative relationship between real domestic stock returns and real exchange rate movements when he employed regression analysis for eight industrialized countries from 1973 to 1983 to detect the impact of several economics variables including the exchange rates on stock prices. (Taylor and Tonks, 1989) found that there was no significant increase in the correlation of stock market returns as a result of the abolition of the UK exchange control.

Empirically, many studies employed regression and correlation as a mainly statistical technique to find out the connection between stock prices and exchange rates. A large number of researchers have begun to use complicated econometric tools to find out the relationship between the variables and showed diverse results. (Bahmani-Oskooee and Sohrabian, 1992), using monthly values of S\&P 500 index and US dollar effective exchange rate over the period of 1973-1998, and employing co-integration analysis and the Granger causality test, showed that there was a bidirectional causality in the short run and no long run relationship between these two variables. On the other hand, (Chow et al., 1997) conducted this issue in the same markets with a longer time horizon, and found a positive relationship between stock returns and real exchange rate returns. (Ajayi and Mougoue, 1996) employed the co-integration and causality tests on daily stock indices and exchange rates in eight industrial economies during the period 19851991. They found a negative short-run and positive long-run effect of an increase in domestic stock prices on domestic currency value. (Yu, 1997) 
investigated in countries such as Hong Kong, Tokyo and Singapore markets by using daily data during 1983-1994. The analysis of his study stated that there was a bidirectional relationship in Tokyo, no causation in the Singapore markets but changes in exchange rates causing changes in stock prices. (Abdalla and Murinde, 1997) used co-integration test to examine the linkage between stock prices and exchange rates for four Asian countries, namely India, Pakistan, South Korea and the Philippines, over a period of 19851994. They have found a unidirectional causality from exchange rates to stock prices in India, South Korea, Pakistan and a positive relationship in the Philippines. (Ajayi et al., 1998) when studied USA, Korea and Malaysia markets found that there was a unidirectional causality from the stock prices to foreign exchange markets in USA and Korea and no linkage between the variables in Malaysia.

There were a number of studies regarding to the interaction between stock prices and exchange rates from 2000 to 2016. (Ibrahim, 2000) performed bi-variate and multivariate co-integration and the Granger Causality test to determine the direction of the causality between stock prices and exchange rates in Malaysia. The author used data from 1979 to 1996. The results from bi-variate models showed that there was no long run relationship between the Malaysia stock market and any of the exchange rate, yet there existed some evidences of co-integration. (Wu. Y, 2000) applied the error correction model to explore the asymmetric effects of four different exchange rates on Singapore stock prices and the effect's sensitivity to economic instability. Both the Singapore currency appreciation against the U.S dollar and Malaysian ringgit and depreciation against the Japanese yen and Indonesian rupiah lead to a long run increase in stock prices for most selected periods of the 1990s. Moreover, (Muhammed and Rasheed, 2002) studied the interaction between stock prices and exchange rates for four countries including Bangladesh, Sri Lanka, India and Pakistan. They applied cointegration test, error correction modeling and a Granger causality test during the period of $1994-2000$. They found that there was no association between the variables for Pakistan and India while bidirectional long run causality in the Bangladesh and Sri Lanka was observed. The authors concluded that the variables are unrelated in the short run for the countries that they selected. In Malaysia context, (Ibrahim and Aziz, 2003) employed cointegration analysis and Vector Auto Regression modeling with using monthly data from January 1977 to August 1998 to investigate the interactions between Malaysian equity market and four macroeconomic variables: real output, price level, money supply and exchange rate. They observed that unstable interactions between the stock prices and exchange rates existed during that crisis period. (Alok Kumar Mishra, 2004) employed Granger causality test and Vector Auto Regression technique on monthly 
stock return, exchange rate, interest rate and demand for money over the period from April 1992 to March 2002. The author found that there existed a unidirectional causality between the exchange rate and interest rate and between the exchange rate return and demand for money, and there was no Granger's causality between the exchange rate return and stock return. (Daniel, 2005) investigated the nature of the causal relationships among stock prices and effective exchange rates in EU countries (respectively Austria, France, Germany, the UK, Czech Republic, Hungary, Poland, and Slovakia), and in the United States. He found that there was a strong unidirectional causality in countries with developed capital and foreign exchange markets, both long run and short run linkage between variables were considered by using monthly data. (Ming-Shiun Pan et al., 2006) applied Granger causality tests, a variance decomposition analysis, and an impulse response analysis to examine dynamic linkages between exchange rates and stock prices for seven Eastern Asian countries, including Hong Kong, Japan, Korea, Malaysia, Singapore, Taiwan, and Thailand, over the period from January 1988 to October 1998. Their empirical results showed a significant causal relation from exchange rates to stock prices for Hong Kong, Japan, Malaysia, and Thailand before the 1997 Asian financial crisis. (Md. Lutfur Rahman and Jashim Uddin, 2009) investigated the interactions between stock prices and exchange rates in three emerging countries of South Asia, namely Bangladesh, India and Pakistan. The authors showed that there was no cointegrating relationship between stock prices and exchange rates by Johansen procedure. Based on Granger causality test they also found no causal relationship between stock prices and exchange rates. (Hua Zhao, 2010) discovered the dynamic linkage between the exchange rate and stock price in China. He employed the VAR and GARCH modeling to estimate and draw the results that there was not a stable long-term equilibrium relationship between RMB real effective exchange rate and stock price. At the same time, in Turkey, by using Granger's causality testing methodology, (Kose, Murat and Hakan, 2010) found that there was a unidirectional causality running from stock prices to exchange rates. (Qazi Zarrar Zia, 2011) observed that there was no long run relationship between stock prices and exchange rates in Pakistan market. (Husam Rjoub,2012) studied the dynamic relationship between the Turkish stock price and the exchange rates, and also considered the US stock prices a world market, in the long and short run. The results showed that the long run relationship was maintained and there were bidirectional relationships between exchange rate and Turkish stock prices. (Umar Bida Ndako, 2013) examined the dynamic relationship between stock prices and exchange rates for five Sub-Saharan African financial markets: Ghana, Kenya, Mauritius, Nigeria and South Africa. With using monthly data from 2000 to 2009, and applying both the 
Vector Auto Regression and the Dynamic Conditional Correlation models, the results showed that there was no evidence of cointegration between stock prices and real exchange rates of all the five countries in the sample, and that the correlation coefficients are not constant in the period under study.

In a recent year, (Serpil Kahraman Akdogu and Ayse Ozden Birkan, 2016) applied a series of non-causality tests to determine the direction of the relationship between stock price indices and exchange rates in emerging market economies. Their empirical findings indicated that there was no universal pattern for the causal relationship between stock prices and exchange rates in emerging market economies. The monthly data set they used for the 21 countries in the MSCI Emerging Markets Index spread over period from January 2003 to June 2013. In order to gain strong results, the authors used the statistical method of the Causality test and Vector Auto Regression model.

This study aims at contributing to the available literature by filling the gap of exploring knowledge about casual linkage between two main markets in the selected countries. The other contribution is considering monthly data combined with Granger Causality Test and Vector Auto Regression model to examine the relationship in the long run. Furthermore, the results of this study will be important for investors, multinational companies and economic policymakers.

\section{Methods}

Traditionally to examine the issue of the causation of dynamic linkages between stock prices and exchange rates, the Granger causality test and Vector Auto Regression (VAR) technique have been employed in the relevant literature. The logic behind the use of VAR in the presence of the Granger Causality test is that in the case of VAR modeling, we do not have information on the endogenous and exogenous variables, and VAR has some of the tools including impulse response functions and variance decompositions, which is not there in Granger's Causality.

\section{Granger's Causality Test}

Granger's Causality Test states that if $\mathrm{X}$ and $\mathrm{Y}$ are two-time series variables tested in the context of linear regression models. In the Grangersense $X$ is a cause of $Y$ if it is useful in forecasting $Y$. In this framework means that $X$ is able to increase the accuracy of the prediction of $\mathrm{Y}$ with respect to a forecast, considering only past values of $Y$. The empirical results presented in this paper are calculated within a simple Granger-causality test in order to test whether stock prices Granger cause exchange rates and vice versa. The following two equations can be specified: 


$$
\begin{aligned}
& S P_{t}=\alpha+\sum_{i=1}^{m} \beta_{i} S P_{t-i}+\sum_{j=1}^{n} \tau_{j} \mathrm{ER}_{t-j}+\mu_{t} \\
& E R_{t}=\theta+\sum_{i=1}^{p} \phi_{i} E R_{t-i}+\sum_{j=1}^{q} \varphi_{j} S P_{t-j}+\eta_{t}
\end{aligned}
$$

where $S P_{t}$ and $E R_{t}$ are the stock price and exchange rate to be tested, and $\mu_{t}$ and $\eta_{t}$, are mutually uncorrelated white noise errors, and $t$ denoted the time period. Based on the estimated OLS coefficients for the equations (1) and (2) four different hypotheses about the relationship between ER and SP can be formulated:

- Unidirectional Granger-causality from ER to SP. In this case exchange rates increase the prediction of the stock prices but not vice versa. Thus $\sum_{j=1}^{n} \tau_{j} \neq 0$ and $\sum_{j=1}^{q} \varphi_{j}=0$

- Unidirectional Granger-causality from SP to ER. In this case the stock prices increase the prediction of the exchange rates but not vice versa. Thus,

$$
\sum_{j=1}^{n} \tau_{j}=0 \text { and } \sum_{j=1}^{q} \varphi_{j} \neq 0
$$

- $\quad$ Bidirectional causality. In this case $\sum_{j=1}^{n} \tau_{j} \neq 0$ and $\sum_{j=1}^{q} \varphi_{j} \neq 0$, so in this case stock prices increase the prediction of the exchange rates and vice versa. - Independence between ER and SP. In this case, there is no Grangercausality in any direction, thus

$$
\sum_{j=1}^{n} \tau_{j}=0 \text { and } \sum_{j=1}^{q} \varphi_{j}=0 \text {. }
$$

From obtaining one of these results it seems possible to detect the causality relationship between stock prices and the exchange rates. There are two crucial steps concerned mainly with Granger's causality test. The stationary data is required for equations (1) and (2) in the first step. Second, selecting the lag length used in Granger methodology from equations (1) and (2) plays a prominent role. For selecting the appropriate lag length, there are different kinds of lag length criteria available such as Akaike's information criteria, Final prediction error, Likelihood ratio test, etc.

\section{Vector Auto Regression (VAR)}

The investigation uses Vector Auto Regression (VAR) model to examine the presence of linear Granger's Causality. VAR system comprised a set of regression equation in which all the variables are considered to be 
independent, each independent variable is rigorously explained by its lagged or past values and the lagged values of all other independent variables included in the model. A VAR model including stock prices and exchange rates can be represented as:

$$
\begin{aligned}
& S P_{t}=\alpha_{10}+\alpha_{11} S P_{t-1}+\alpha_{12} E R_{t-1}+\varepsilon_{1 t} \\
& E R_{t}=\alpha_{20}+\alpha_{21} S P_{t-1}+\alpha_{22} S P_{t-1}+\varepsilon_{2 t}
\end{aligned}
$$

where $S P_{t}$ is the stock price at the time period $t, E R_{t}$ is the exchange rate at the time period $t, \alpha_{i j}$ is the element in row $i$ and column $j$ of the matrix A, $\varepsilon_{1 t}$ and $\varepsilon_{2 t}$ are white noise error term and both have zero mean and constant variances and are individually serially uncorrelated. In order to conduct VAR estimation, the procedure of estimation requires the selection of variables to be included in the system. The next step is to verify the stationary of the variables by employing the unit root test in terms of Augmented DickyFuller (ADF) and Phillips-Perron (PP) tests recommended by (Doan, 1992). Selecting the appropriate lag length is the next step, and to make sure that the lag length of each of the variables is fixed in the system. This requires the use of multivariate versions of the information criteria Brooks (2008). The study carries out a eight-variable VAR system in the financial market in Hungary, Czech Republic, Poland and Romania. These are Budapest stock price (BUX), the Czech Republic stock price (PX), Warsaw stock price (WIG), Romania stock market (BET), US dollar Hungarian exchange rate (USDHUF), US dollar Czech Republic Koruna exchange rate (USDCZK), US dollar Polish Zloty rate (USDPLN) and US dollar Romanian Leu rate (USDRON). In this study, the volatility of these variables is estimated by using historical data. Monthly stock asset returns $\left(\mathrm{r}_{\mathrm{it}}\right)$ and the rate of changes in exchange rate $\left(\mathrm{e}_{\mathrm{it}}\right)$ of eight variables are calculated as follows:

$$
r_{i, t}=\ln \frac{p_{i, t}}{p_{i-1, t-1}}, i=\overline{1, n}
$$

and

$$
e_{i, t}=\ln \frac{f_{i, t}}{f_{i-1, t-1}}, i=\overline{1, n}
$$

where $p_{i, t}$ is the stock price index for the stock market $i$ at time $t . r_{i, t}$ is the stock market return. $f_{i, t}$ is the exchange rates of currency $i$ at time $t$ and $e_{i, t}$ is the rate of the exchange rate changes. The datasets used in this study are the monthly closing stock price indices and end-of-period nominal exchange rates, relative to the US dollar in Hungarian, Czech Republic, Polish and Romanian market. The data for our empirical investigation is obtained from Bloomberg, accounted by the Department of Finance, Corvinus University of 
Budapest, the sample period is from October 31, 2008 to September 18, 2017 which constitutes a total of $\mathrm{n}=107$ (excluding weekends and holidays). Then we transform all the data series into natural log form. Finally, we used Eview software for estimating VAR model.

\section{Results}

The descriptive statistics of monthly price of the eight series are given in Table 1 (Panels A and B). Several traits can be identified from these summary statistics. It can be seen from Panel A, Poland has the highest mean among the four European stock market, followed by Czech, Hungary and Romania. Additionally, the volatility of the selected stock markets given the standard deviation are relatively low. For all the four series, skewnesses of monthly prices are not equal to zero and kurtosises are greater than three. This suggests that these stock return series do not follow the normal distribution except for Hungary. This result is confirmed by the Jarque-Bara test statistics which reject the hypothesis of normality of stock returns at $1 \%$ the level of significance. We can see from the statistics reported in Panel B that all currencies illustrate a positive mean return. Poland suffers from the highest currency depreciation while Hungary appears to suffer the most volatile currency fluctuations during the sample period. Finally, Jarque-Berra tests show that the data of foreign exchange rates considered are found to be non-normal for all countries.

Table 1. Descriptive statistics for the monthly stock returns and FX rate

\begin{tabular}{ccccc}
\hline & Hungary & Poland & Czech & Romania \\
\hline $\begin{array}{c}\text { Panel A: stock } \\
\text { returns }\end{array}$ & & & & \\
Mean & 0.009783 & 1.009027 & 1.003127 & 0.009588 \\
Std.dev & 0.060618 & 0.051277 & 0.054463 & 0.067887 \\
Skewness & -0.076292 & 0.559678 & 0.394843 & -0.300194 \\
Kurtosis & 3.609222 & 4.614461 & 5.219561 & 6.451264 \\
J-B & 1.758515 & 17.20668 & 24.74400 & 54.71129 \\
Probability & 0.415091 & 0.000183 & 0.000004 & 0.000000 \\
Panel B: FX rates & & & & \\
Mean & 0.002368 & 0.002402 & 0.001363 & 0.002699 \\
Std.dev & 0.045333 & 0.043259 & 0.037531 & 0.036883 \\
Skewness & 1.107546 & 0.741563 & 0.462448 & 0.627649 \\
Kurtosis & 6.607758 & 4.866111 & 4.012692 & 4.753686 \\
J-B & 79.90470 & 25.33239 & 8.386037 & 20.73653 \\
Probability & 0.000000 & 0.000003 & 0.015101 & 0.000031 \\
\hline
\end{tabular}

Note: J-B statistics is the Jarque-Bara test for normality

Figure 1 presents the plot of stock and exchange rate returns. These indicate some circumstances where their returns fluctuate. 

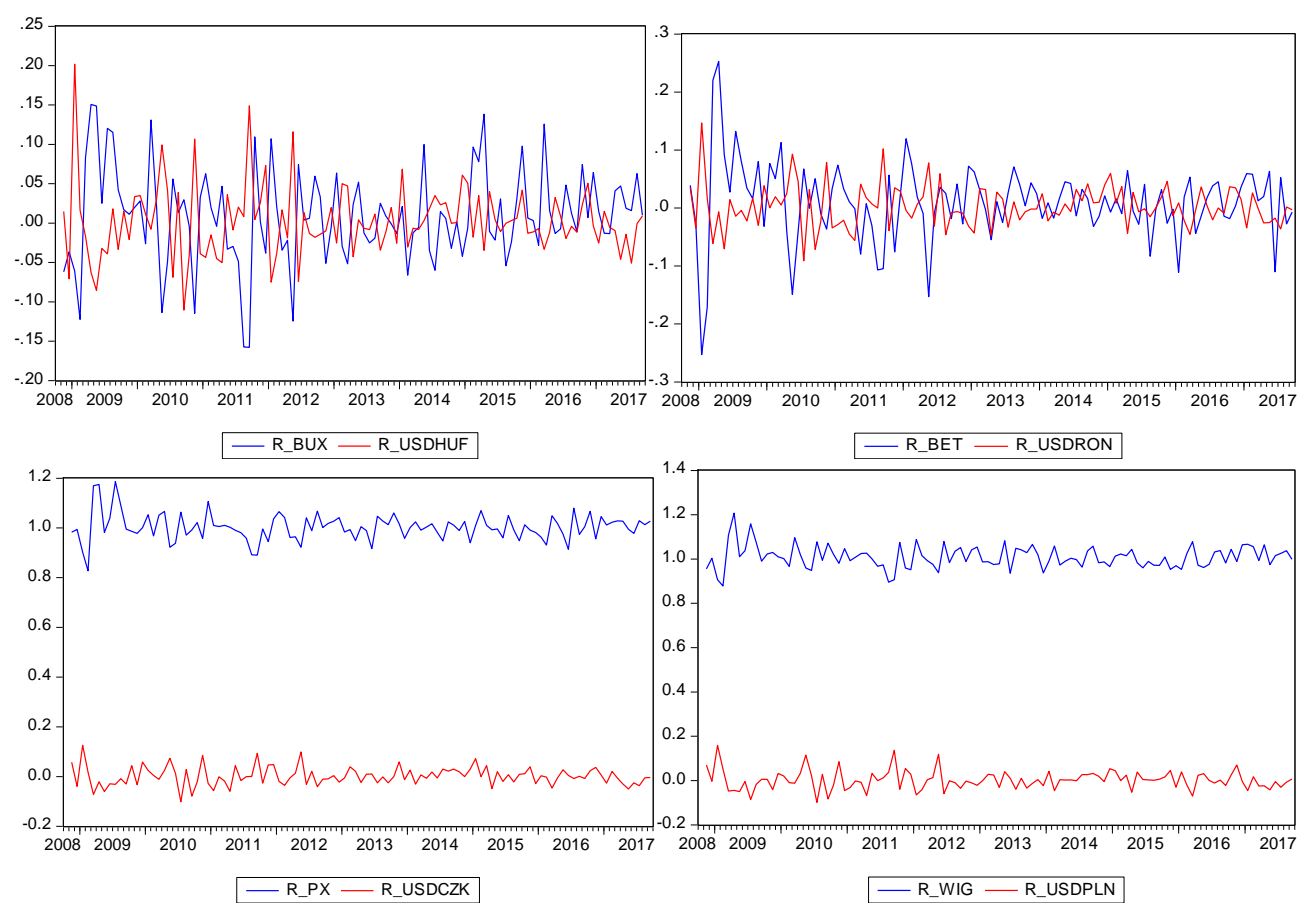

Figure 1. Monthly stock and exchange rate returns

Table 2 summarizes the unit root tests for the monthly logarithmic returns of eight series to examine the time series properties of concerned variables prior to reporting the results. The Augmented Dickey-Fuller (ADF) and Phillips-Perron (PP) tests were employed to test the null hypothesis of a unit root against the alternative hypothesis of stationarity. The ADF and PP test indicate the stock market prices and foreign exchange rate are nonstationary at their level. Nevertheless, stock market returns $\left(r_{i t}\right)$ and foreign exchange $\left(\mathrm{e}_{\mathrm{it}}\right)$ returns are stationary (i.e. $\mathrm{I}(0)$ ) using the level of significance of $1 \%$ all the series. Therefore, we can directly perform the Granger causality test.

Table 2. Unit root and stationarity test

\begin{tabular}{rcccccccc}
\hline Variables & \multicolumn{2}{c}{ Hungary } & \multicolumn{2}{c}{ Poland } & \multicolumn{2}{c}{ Czech } & \multicolumn{2}{c}{ Romania } \\
\cline { 2 - 8 } & ADF & PP & ADF & PP & ADF & PP & ADF & PP \\
\cline { 2 - 8 } $\mathrm{r}_{\mathrm{it}}$ & $-8.346^{*}$ & $-8.346^{*}$ & $-9.154^{*}$ & $-9.113^{*}$ & $-9.149^{*}$ & $-9.160^{*}$ & $-7.811^{*}$ & $-7.518^{*}$ \\
$\mathrm{e}_{\mathrm{it}}$ & - & - & - & - & - & - & - & - \\
& $11.230^{*}$ & $11.532^{*}$ & $10.514^{*}$ & $10.624^{*}$ & $11.324^{*}$ & $11.314^{*}$ & $11.515^{*}$ & $11.516^{*}$ \\
\hline
\end{tabular}

Note: $\mathrm{r}_{\mathrm{i} t}$ : stock market return, $\mathrm{e}_{\mathrm{it}}$ exchange rate of currency. $\left({ }^{*}\right)$ indicates statistical significance at the $1 \%$ level. The lag augmentation is on the basis of optimum lag length selection. The critical values for unit root tests at 1 per cent, 5 per cent and 10 per cent levels are $-3.493,-2.888$ and -2.581 respectively.

Before conducting the Granger causality tests and VAR model, we have to determine the optimum lag length for stock returns and exchange 
rates variables. The lag selection is based on the Akaike Information Criterion (AIC) and sequential modified LR test statistic criterion. Thus the appropriate lag structure ten in order to detect the causal relationship between the stock returns and exchange rate variables. As we can see from Table 3, the Granger Causality test results for the concerned variables in the four countries. For the full sample period, the reported F-values as well as pvalue suggest that there is no Granger causality between stock price and foreign exchange rate. The results confirm that there is no significant causal relationship between exchange rate and stock price movements (as corresponding F-statistics are significant at $1 \%$ level of significance).

Table 3. The results of Granger-causality tests for Hungary, Czech, Poland and Romania

\begin{tabular}{cccc}
\hline Country & Null Hypothesis $\left(\mathrm{H}_{0}\right)$ & F-Statistics & Results \\
\hline Hungary & BUX does not Granger Cause USDHUF & $\begin{array}{c}1.14828 \\
(0.3389)\end{array}$ & Accept $\mathrm{H}_{0}$ \\
& & 0.91296 & Accept $\mathrm{H}_{0}$ \\
& USDHUF does not Granger Cause BUX & $(0.5259)$ & \\
\hline Czech & PX does not Granger Cause USDCZK & 0.40521 & Accept $\mathrm{H}_{0}$ \\
& & $(0.9402)$ & \\
& USDCZK does not Granger Cause PX & 0.44580 & Accept $\mathrm{H}_{0}$ \\
& & $(0.9188)$ & \\
\hline Poland & WIG does not Granger Cause USDPLN & 0.79155 & Accept $\mathrm{H}_{0}$ \\
& & $(0.6369)$ & \\
& USDPLN does not Granger Cause WIG & 1.46718 & Accept $\mathrm{H}_{0}$ \\
& & $(0.1684)$ & \\
\hline Romania & BET does not Granger Cause USDRON & 0.70075 & Accept $\mathrm{H}_{0}$ \\
& & $(0.7208)$ & \\
& USDRON does not Granger Cause BET & 1.04202 & Accept $\mathrm{H}_{0}$ \\
& & $(0.4174)$ & \\
\hline
\end{tabular}

Note: reject $\mathrm{H}_{0}$ (no Granger cause) at $1 \%$ level, $\mathrm{p}$-value for the test are in parentheses.

In the bivariate VAR, impulse response can illustrate further information background on the short run relationship which is not conducted by Granger causality test. Considering the signs of responses, innovations to stock returns in Figure 2 have a negative impact on the foreign exchange rates in the short run as the impulse response is negative, and the effect of the shock equals zero in the long run periods. 


\section{Hungary}

Response of USDHUF to BUX

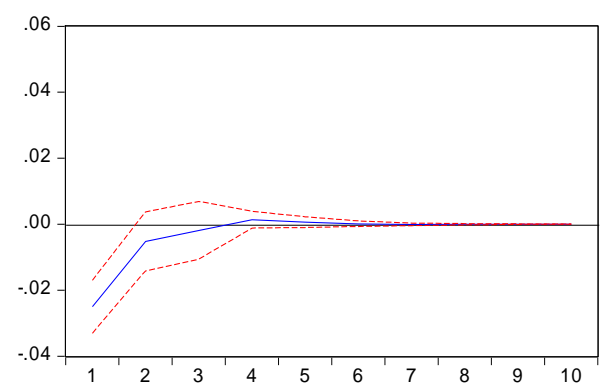

\section{Romania}

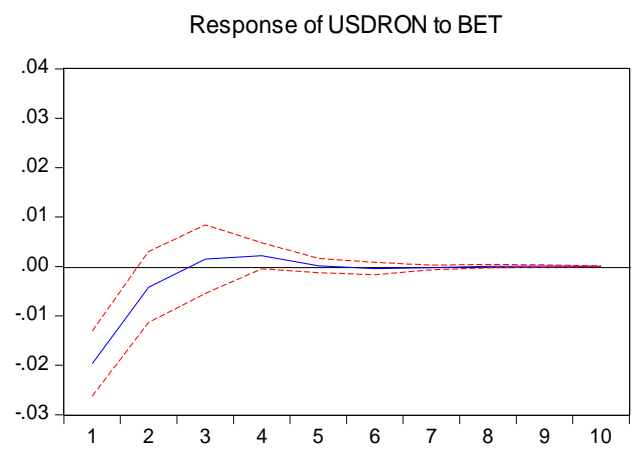

\section{Poland}



\section{Czech Republic}

Response of USDCZK to PX

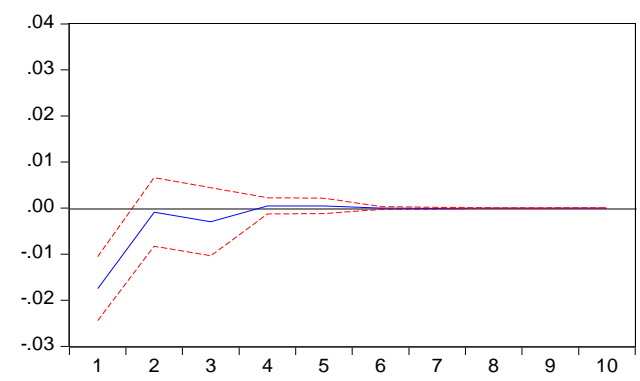

Figure 2. Impulse response to Cholesky one S.D. innovations \pm 2 S.E; response of SP to FX and FX to SP respectively
Response of BUX to USDHUF



Response of BET to USDRON

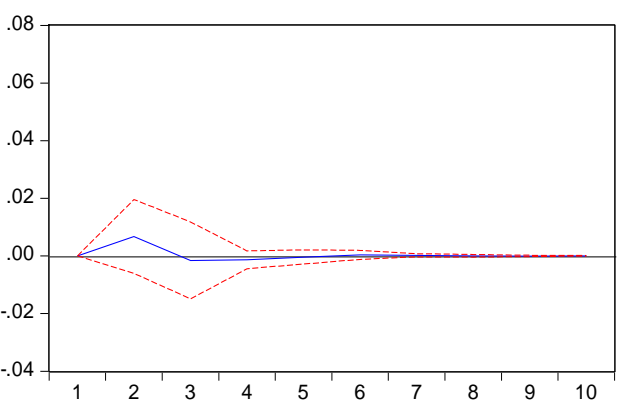

Response of WIG to USDPLN



Response of PX to USDCZK

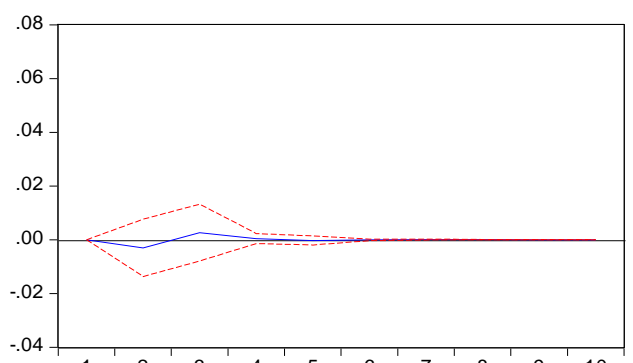




\section{Conclusion}

This paper examined the dynamic relationship between the stock market and foreign exchange rates for four Eastern European countries over the period from October 31, 2008 to September 18, 2017. We used monthly data and employed Vector Auto Regression modeling and Granger's Causality test approach. In the model, the stationarity of variables is tested by applying the ADF and PP test, the optimum lag length is determined. It is interesting that the four countries would have the analogous results. In essence, our empirical results shed light on that there is no Granger causality between stock return and exchange rate return in the four countries, while the literature and some of the previous researches suggest the existence of the significant association between the two markets. This result supports the arguments of (Franck and Young, 1972), (Abdalla and Murinde, 1997), (Ajayi et al., 1998), (Ibrahim, 2000), (Muhammed and Rasheed, 2002), (Ibrahim and Aziz, 2003), (Alok Kumar Mishra, 2004), (Daniel, 2005), (Md. Lutfur Rahman and Jashim Uddin, 2009), (Hua Zhao, 2010), (Kose, Murat and Hakan, 2010), (Qazi Zarrar Zia, 2011), (Umar Bida Ndako, 2013) and (Serpil Kahraman Akdogu and Ayse Ozden Birkan, 2016).

For further affirmation of the result of the VAR modeling reports that although stock prices and exchange rates are interrelated to each other, no consistent linkage between them. Impulse response technique demonstrates that stock return affects exchange rate return in the short term and the effect of the shock equals zero in the long run periods. The results of Granger's Causality test and VAR modeling are similar.

Analysis of the link between stock returns and foreign exchange rates would have important implications for the policymakers and market participants. Understanding this relationship would help in pricing, optimal investment and decision making. Policymakers should not be cautious in their implementation of exchange rate policies. Moreover, the market participants can apply this data for forecasting the future movement of the behavior of stock prices and foreign exchange rates.

\section{References:}

1. Aggarwal R. (1981). Exchange Rates and Stock Prices: A Study of the US Capital Markets under Floating Exchange Rates. Akron Business and Economic Review, vol. 12: 7-12.

2. Ajayi, A.R. and M. Mougoue (1996). On the Dynamic Relation between Stock Prices and Exchange Rates. The Journal of Financial Research, vol.19(2): 193-207.

3. Abdalla, I.S.A., and V. Murinde. (1997). Exchange Rate and Stock Price Interactions in Emerging Financial Markets: Evidence on India, 
Korea, Korea, Pakistan and The Philippines. Applied Financial Economics, vol.7: 25-35.

4. Ayaji A.R., Joseph F.R., and S. M. Mehdian (1998). On the Relationship Between Stock Returns and Exchange Rates: Test of Granger Causality. Global Finance Journal, vol. 9(2): 241-251.

5. Alok Kumar Mishra (2004). Stock Market and Foreign Exchange Market in India: Are They Related?. South Asia Economic Journal, vol 5(2): 210-232.

6. Bahmani-Oskooee, M., and A. Sohrabian (1992). Stock Prices and the Effective Exchange Rate of Dollar. Applied Economics, vol. 24(4): 459-464.

7. Brooks C. (2008). Introductory econometrics for finance. Second edition. Cambridge university press.

8. Chow, E.H, W.Y. Lee and M.E. Stolt (1997). The Exchange Rate Risk Exposure of Asset Returns. Journal of Finance, vol.70(1): 10523.

9. Daniel Stavarek (2005). Stock Prices and Exchange Rates in the EU and the USA: Evidence of their Mutual Interactions. Czech Journal of Economics and Finance, 55: 3-4.

10. Doan, T. (1992). Rats: User's manual (Estima, Evanston, IL).

11. Frank, P. and A. Young (1972). Stock Price Reaction of Multinational Firms to Exchange Realignments. Financial Management, vol. 1(3): 66-73.

12. Ibrahim, M.H (2000). Cointegration and Granger Causality Tests of Stock Price and Exchange Rate Interactions in Malaysia. Asian Economic Bulletin, vol. 17(1): 36-46.

13. Ibrahim, M.H., and H. Aziz (2003). Macroeconomics Variables and the Malaysian Equity Market: A View Through Rolling Subsamples. Journal of Economic Studies, 1: 6-27

14. Granger, C.W.J., Huan, B., \& C.W.Yang (2000). A Bivariate Causality between Stock Prices and Exchange Rates: Evidence from Recent Asian Flu. The Quarterly Review of Economics and Finance, vol. 40(3): 337-354.

15. Hua Zhao (2010). Dynamic relationship between exchange rate and stock price: Evidence from China. Research in International Business and Finance, vol. 24(2): 103-112.

16. Husam Rjoub (2012). Stock prices and exchange rates dynamics: Evidence from emerging markets. African Journal of Business Management, vol. 6(13): 4728-4733.

17. Kose, Murat and Hakan (2010). On the causality between stock prices and exchange rates: evidence from Turkish financial market. Problems and Perspectives in Management, 8:127-135. 
18. Ming-Shiun Pan, Robert Chi-Wing Fok and Y. Angela Liu (2006). Dynamic linkages between exchange rates and stock prices: Evidence from East Asian markets. International Review of Economics and Finance, 16: 503-520.

19. Md. Lutfur Rahman, Jashim Uddin (2009). Dynamic Relationship between Stock Prices and Exchange Rates: Evidence from Three South Asian Countries. International Business Research, vol. 2(2): 167-174.

20. Muhammad. N., and Rasheed. A (2002). Stock prices and exchange rates: Are they related? Evidence from South Asian countries. The Pakistan Development Review, vol. 41(4): 535-550.

21. Ma, K.C. and G.W. Kao (1990). On Exchange Rate Changes and Stock Price Reactions, Journal of Business Accounting, vol. 17(3): 441-49.

22. Qazi Zarrar Zia, Zahid Rahman (2011). The Causality between Stock Market and Foreign Exchange Market of Pakistan. Interdisciplinary Journal of Contemporary Research In Business, vol 3(5): 906-919.

23. Solnik, B (1987). Using Financial Prices to Test Exchange Models. A Note. Journal of Finance, vol. 42 (1): 141-149.

24. Serpil Kahraman Akdogu1 and Ayse Ozden Birkan (2016). Interaction between Stock Prices and Exchange Rate in Emerging Market Economies. Research in World Economy, vol. 7(1): 80-94.

25. Taylor, M.P. and I. Tonks (1989). The Internationalization of Stock Markets and the Abolition of UK Exchange Control. Review of Economics and Statistics, 71: 332-36.

26. Umar Bida Ndako (2013). Dynamics of Stock Prices and Exchange Rates Relationship: Evidence From Five Sub-Saharan African Financial Markets. Journal of African Business, vol. 14(1): 47-57.

27. Wu, Y. (2000). Stock prices and exchange rates in a VEC model: The case of Singapore in the 1990s. Journal of Economics and Finance, 24: 260-274.

28. Yu, Q. (1997). Stock Prices and Exchange Rates: Experience in Leading East Asian Financial Centers Tokyo, Hong Kong and Singapore. Singapore Economic Review, 41: 47-56. 